\title{
Computational Methods for Masonry Vaults: A Review of Recent Results
}

\author{
A. Tralli ${ }^{1}$, C. Alessandri ${ }^{1}$ and G. Milani ${ }^{2, *}$ \\ ${ }^{I}$ Dept. of Engineering, University of Ferrara, Via G. Saragat 1, 44122 Ferrara, Italy \\ ${ }^{2}$ Dept. of Architecture, Built Environment and Construction Engineering, Polytechnic of Milan, Piazza Leonardo da \\ Vinci 32, 20133 Milano, Italy
}

\begin{abstract}
The present paper makes a critical review of some methods and models, now available in the technical literature and commonly used in the analysis of masonry vaults up to their collapse, by highlighting advantages and drawbacks of each approach. All methods adopted to describe the mechanical behavior of masonry structures, in order to be reliable, must take into account the distinctive aspects of masonry, namely the scarce (or zero) tensile strength, the good resistance in compression and the occurrence of failure mechanisms through rotation-translation of rigid macro-blocks. Classic notension material models disregard the small existing tensile strength and make the assumption of (1) infinitely elastic behavior in compression and (2) isotropy, giving thus the possibility to deal with either semi-analytical approaches (especially for arches) or robust numerical procedures. More advanced but rather complex models are nowadays able to deal also with anisotropy induced by texture, small tensile strength and softening in tension, as well as by finite strength in compression. Traditionally - and nowadays it is still an opinion commonly accepted, in contrast with step by step complex procedures, Limit Analysis has proved to be the most effective Method for a fast and reliable evaluation of the load bearing capacity of vaulted masonry structures: classic lower and upper bound theorems recall respectively the concepts of equilibrium and occurrence of failure mechanisms with rigid elements. The so-called Thrust Network Method moves its steps from lower bound theorems, whereas FE limit analysis approaches with infinitely resistant elements and dissipation on interfaces take inspiration from the upper bound point of view. An alternative to Limit Analysis is represented by traditional FEM combined with either elastic-plastic or damaging models with softening, commonly used for other materials but recently adapted also to masonry. They are able to provide a large set of output numerical information but further studies are still needed to ensure their proper application.
\end{abstract}

Keywords: Masonry single and double curvature structures (arches, vaults, domes), numerical models, state of the art.

\section{INTRODUCTION}

Masonry curved elements - such as arches, domes and vaults - represent one of the most widespread structural typologies in the historical buildings of both Eastern and Western architecture. Since many of these constructions, if not the majority of them, date back to centuries ago, the interest for their preservation and rehabilitation has always been great and is growing over time along with the need for developing new efficient tools to analyze and evaluate their load-bearing capacity.

Actually this has never been a simple task, mainly because masonry is a heterogeneous material consisting of units of different types, such as bricks, ashlars, adobes, regular or irregular stones etc., and joints made of clay, bitumen, chalk, lime/cement based mortar, glue etc. Both units and joints can have completely different mechanical, chemical and physical behaviour and the number of their possible

*Address correspondence to this author at the Department ABC, Politecnico di Milano, Piazza Leonardo da Vinci 3220133 Milan, Italy;

Tel: +39 022399 4290; Fax: +39 022399 4220; Mobile: +39 3495516064;

E-mail: gabriele.milani@polimi.it combinations, in terms of geometry, assembling and characteristics can be sensibly high, so as to raise some doubts about the pertinence of the term "masonry". However, the different types of masonry, although exhibiting different mechanical behaviours, have in general a very low tensile strength as a common feature and this property has always been so important to influence the shape of ancient constructions. Moreover, there are many difficulties in performing advanced mechanical tests in ancient structures because of the great variety of masonries, the variability of the masonry itself in a specific structure and the impossibility of reproducing such a variability in just one specimen.

The structures belonging to the Architectural Heritage, by their very nature and history (materials and assembling), offer a number of very interesting challenges in conservation, diagnosis, analysis, monitoring and strengthening. The recently published Recommendations for the Analysis, Conservation and Structural Restoration of Architectural Heritage by ICOMOS [1] and the Italian Guidelines for cultural heritage buildings [2] recommend an iterative process between data acquisition and diagnosis on one hand and structural behavior and safety on the other. In particular, diagno- 
sis and evaluation of the structural safety are two consecutive and related stages which determine the effective need for some interventions and their extent.

To date, nevertheless, the analysis of masonry structures represents a still unsolved issue: a widely accepted approach to the study of their stability is still lacking. Simple linear elastic models, which form the basis of common structural analyses, cannot in fact be applied to masonry because of its inherent and widely differing response to tension and compression. The problem is well known. More than twenty years ago Giuffrè wrote [3]. "Something deserves to be reviewed in the mechanical training of the Civil Engineer [...] between Mechanics and the chapter of the Theory of Elasticity. Due to the resulting confusion, all the results of the progress achieved since the time of Cauchy in understanding the behavior of elastic structures, with the help of modern computerized algorithms, have been applied "tout court" and indifferently to all constructions, even including ancient cathedrals or temples ". In contrast to the trend of that time, Di Pasquale [4] underlined that "In masonry the form of the resistant structure depends on loads", Fig. (1).

Several methods and computational tools are nowadays available for the assessment of the mechanical behavior of historical constructions and the Authors of this note refer to Roca et al. [5] for an exhaustive and general overview of the State of the Art of the approaches to structural analysis of historic masonry constructions. The methods, which are based on different theories and approaches, exhibit different levels of complexity (from simple graphical methods and manual calculations to complex mathematical formulations and large systems of nonlinear equations), different usability by practitioners (by readily available in any consulting Engineering office to poorly available or available only in a few oriented research centers), require different execution times (from a few seconds of computer time to many hours of processing) and, of course, different costs.

Moreover it is worth noting that a number of Mathematicians studied masonry-like materials in the context of the Theory of Variational Inequalities of Lions and Stampacchia and formulated a proper functional setting, on the basis of a simplified constitutive law for which masonry behaves as nonlinear hyperelastic (homogeneous isotropic) no tension material, i.e. with zero tensile strength and infinite compressive strength, and the cracks are dealt as distributed distor- tions (Heyman [6], Di Pasquale [7], Del Piero [8], Giaquinta and Giusti [9], Anzellotti [10].

Finally it must be observed that an appropriate knowledge of the history of structural Mechanics, design methods and construction technologies is surely necessary to understand the mechanical behavior of historical constructions, and for this the reader is referred to the basic text of Benvenuto [11] or more recent papers of Huerta [12,13].

\section{THE MODERN VAULT THEORY}

The modern history of the calculus of masonry vaults begins with the contributions of the late 1600s English school (Hooke 1676 and 1705, Gregory 1698) that stated the analogy between the inverted shape of a catenary and a compressed arch, employed by Poleni in 1743 for the consolidation of the dome of St. Peter in Rome and reused by Gaudi, the architect of the Sagrada Familia in Barcelona. The first "scientific" graphical attempts to study the equilibrium of masonry domes go back to the early $18^{\text {th }}$ century and are attributed, among others, to Bouguer (1734), Bossut (1778), Coulomb (1773- also taking into account friction) and Mascheroni (1785). These scientists stated monodimensional equilibrium equations, neglecting the role of circumferential forces and anticipating indeed concepts of limit analysis, see Fig. (2).

During the $19^{\text {th }}$ century the theory of elasticity was developed and a new look was given to the statics of arches (Navier 1826); after that, for almost fifty years, the researchers - for instance Mery (1857)- tried to conciliate the traditional approach in terms of limit analysis with the new claims in the name of strength and elasticity.

Anyway, what appeared clear since the beginning, was that cracking occurs on curved masonry elements with their own self-weight in consequence of the very low tensile stresses. In this context, a considerable improvement in the analysis of spherical domes was achieved when Levy (1888) proposed a graphical analysis aimed at finding the circle on which circumferential forces vanish.

As regards masonry arches and vaults (made of stone blocks or solid clay bricks), a sound theoretical framework exists and nowadays -following Huerta [12] or Como [14]- it can be affirmed that the modern theory of limit analysis of masonry structures, which has been developed mainly by

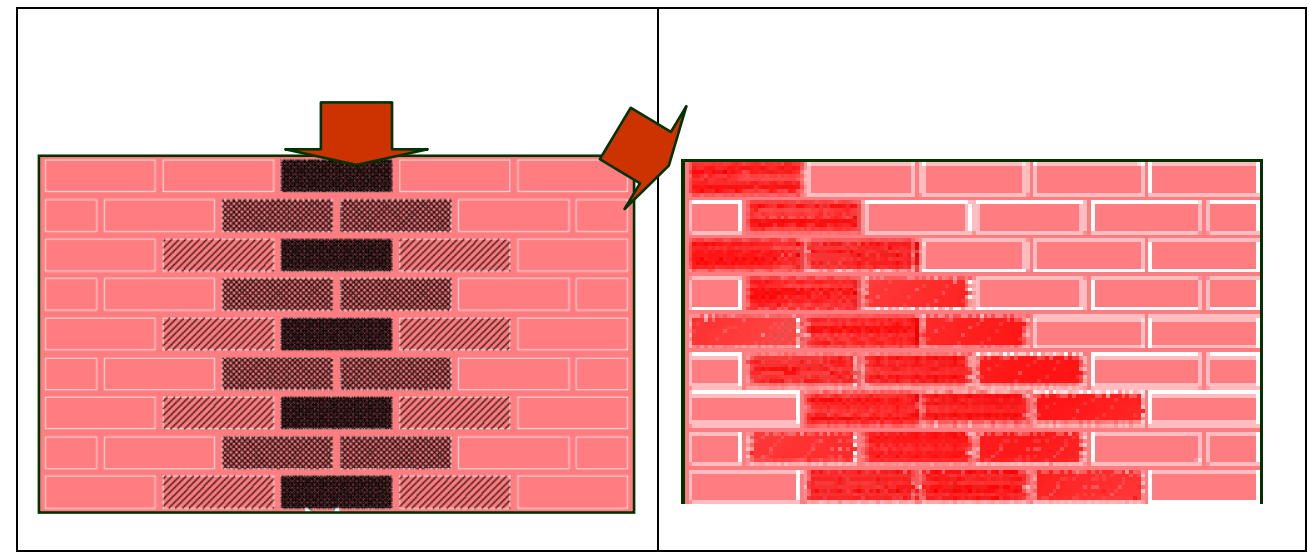

Fig. (1). In masonry, the form of the resistant structure depends on loads (Di Pasquale [4]). 


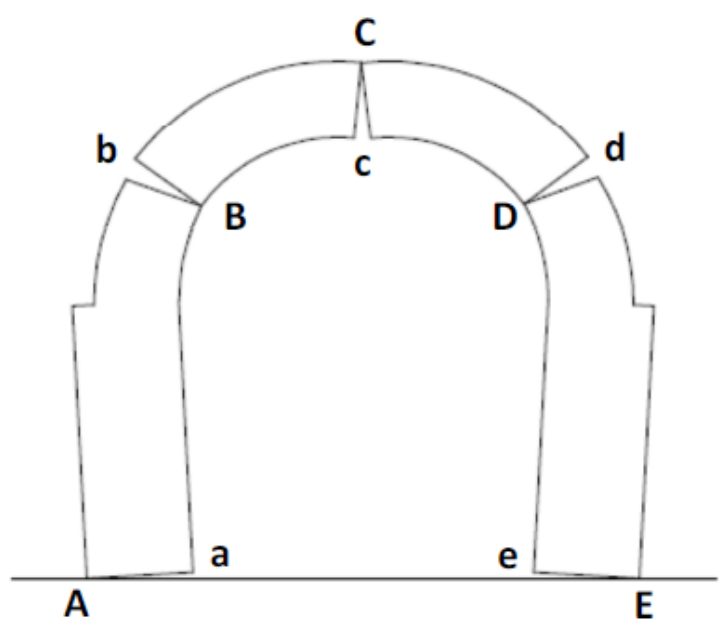

Fig. (2). The contribution of Mascheroni.

Heyman [15], is the most reliable tool to understand and analyze masonry curved structures. For the sake of completeness, it is worth citing also the previous papers of Pippard $[16,17]$ on the analysis of masonry arch bridges and the Ph. D. thesis of Kooharian [18] in 1952 at Brown University where the basic idea appeared for the first time. Finally the possibility of extending limit analysis theorems to no tension materials has been completely proved by Del Piero [8].

According to the Heyman formulation [15], the limit theorems of plasticity can be applied to masonry structures provided the following conditions are verified:

1. The compressive strength of the material is infinite;

2. Sliding between parts is impossible;

3. The tensile strength of masonry is null.

These conditions enable the application of the well known limit theorems of Plasticity- static (lower bound) and kinematic (upper bound) theorems, Fig. (3).

\subsection{Static Theorem}

The structure is safe, meaning that the collapse will not occur, if a statically admissible state of equilibrium can be

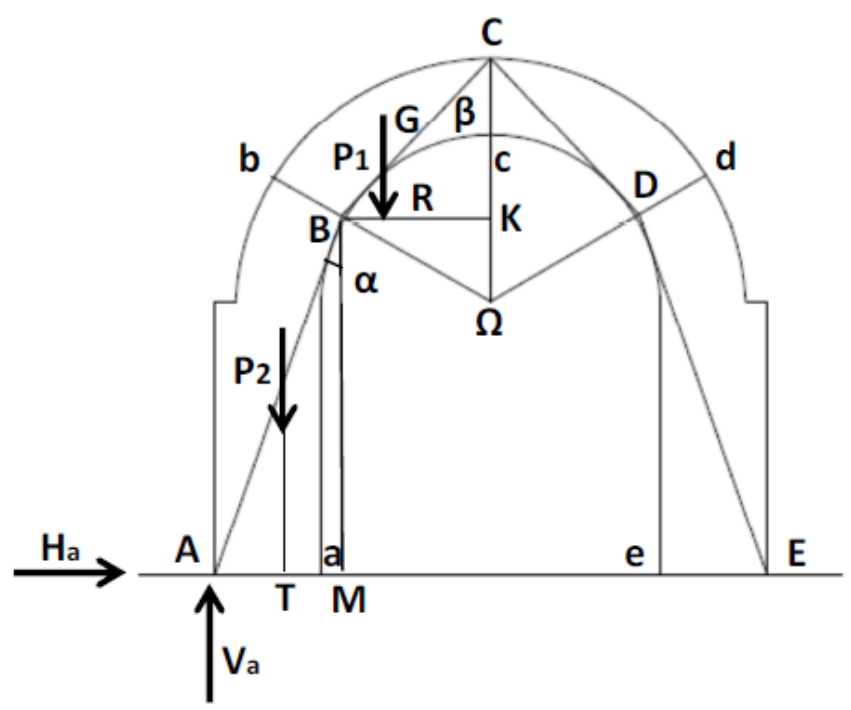

found. This occurs when an inner thrust line to the arch thickness (or an inner thrust surface to the vault) can be determined in equilibrium with the external loads. In practice, the solution is constrained to a particular zone of the structure's section, for example $0,85 \cdot d$, with $d$ the depth of the section, not only to take in to account the imperfections in the real geometry, but also to avoid unrealistic stress concentrations, which would violate the no-crushing assumption (Heyman [19]). Thrust line analysis is a useful tool to explain and examine the stability of one-dimensional (1D) structures, but unfortunately it is practically limited to them.

\subsection{Kinematic Theorem}

If a kinematically admissible mechanism can be found, for which the work developed by external forces is positive or zero, then the arch will collapse. The load multiplier so determined is an upper-bound to the actual one. In practice it is very easy to apply this theorem only to arches or others $1 \mathrm{D}$ structures.

Classical manual methods of analysis, Como [14], allow finding in a suitable way $1 \mathrm{D}$ equilibrium solutions for the different types of vaults; Fanning and Boothby [20] provided a critical overview of the different methods of analysis for

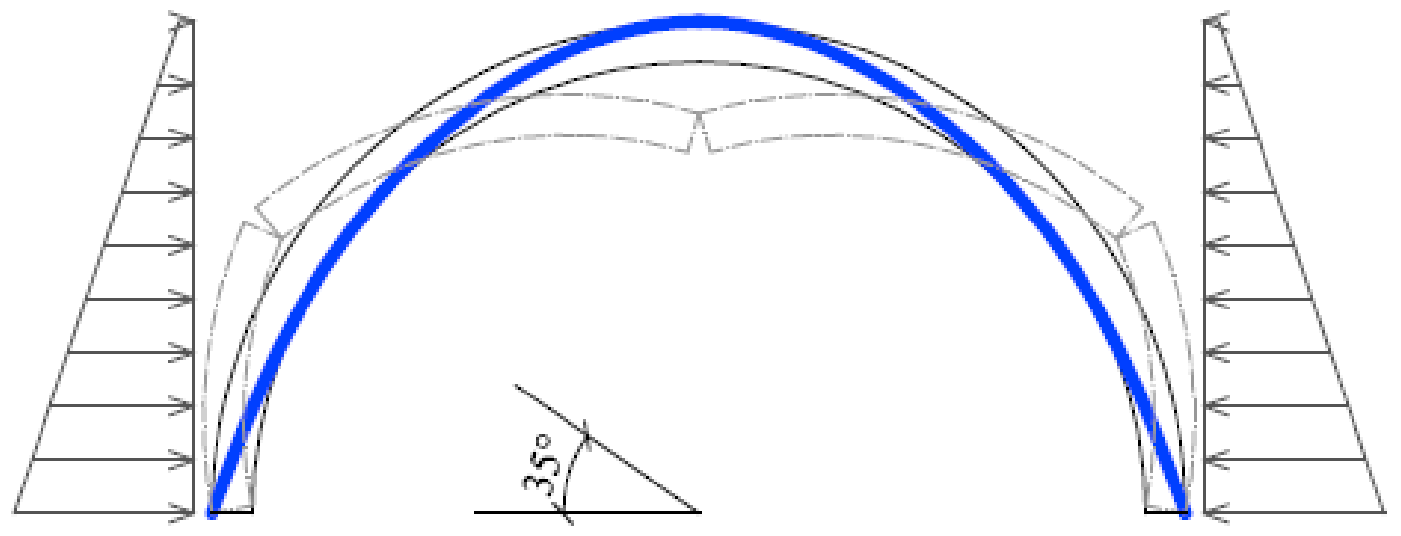

Fig. (3). Thrust line (continuous blue line) and collapse mechanism for an arch. 
masonry arches and vaults. However, simplified limit analysis methods can provide an elegant solution for the complex problems of dome and drum of the Basilica of S. Maria Assunta in Carignano (Genoa), Bagicalupo et al. [21].

It has to be observed that normally for structures made of clay bricks and blocks:

- the collapse generally occurs at small overall displacements.

- The second hypothesis previously discussed (sliding absent) is not always verified. Indeed sliding is possible in some cases, but experimentally shear failure at the joints can be dealt within the context of non-associate plasticity (Gilbert et al. [22], Orduna and Lourenço [23]).

- The infinite compressive strength might be questionable, and even Heyman [19] suggested a method to take it into account, but crushing behavior has a minor importance in the response of masonry structures except for very shallow arches, pillars, towers and massive vertical structures.

The study of masonry vaults should take into account the essentials of the material "masonry", as highlighted by Huerta [12]:

1. Heterogeneity;

2. Almost no resistance to tension and good compressive strength;
3. High friction coefficient;

4. Importance of the overall geometry for achieving the equilibrium.

\subsubsection{Heterogeneity}

Masonry is obviously a heterogeneous composite material (made by clay bricks or stone blocks and mortar) and, according to experimental evidence, exhibits a non-isotropic behavior both in the elastic range and at collapse [24-27], see Fig. (4).

Moreover, in the case of vaults, the texture can be completely different in the different parts of the same vault, Fig. (5).

\subsubsection{Almost No Tension Resistance and Good Compres- sive Strength}

The tensile strength is quite variable and uncertain; usually the crisis occurs in the interface between mortar and brick, which can be modeled according to Lourenço and Rots [28], Sutcliffe et al. [29], Milani et al. [26], Fig. (6a).

\subsubsection{High Friction Coefficient}

According to Vasconcelos \& Lourenço [30] the friction coefficient for historical masonry is $m=0,4-0,6$. However the normality is lost and the flow rule is not associate; in this case, as well known (Radenkovic [31], Salençon [32]). The limit analysis theorems do not hold and LP methods cannot

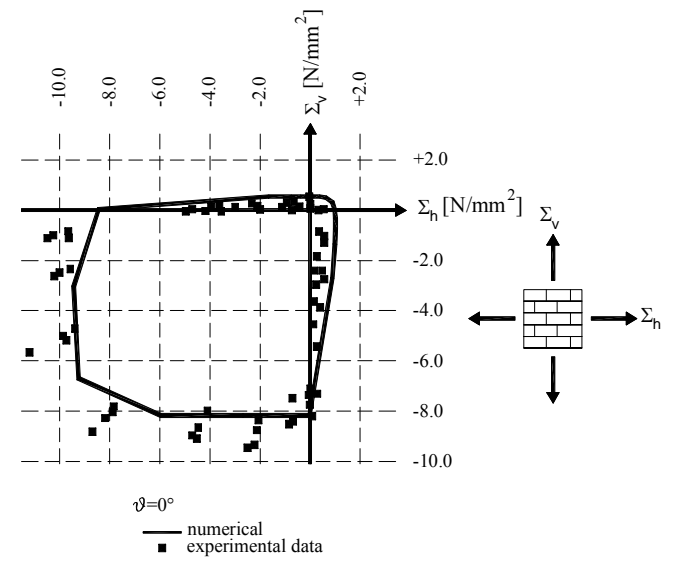

(a)

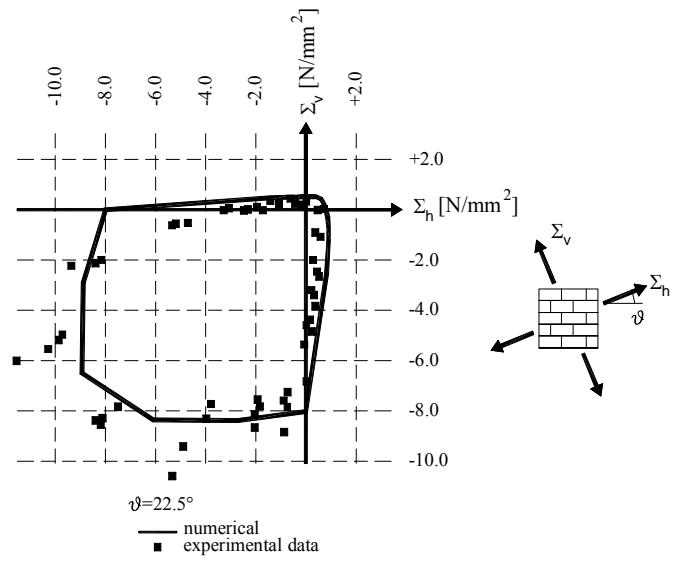

(b)

Fig. (4). Homogenized Figure for Page experimental results [24], (a) $\theta=0^{\circ}$, (b) $\theta=22.5^{\circ}$.
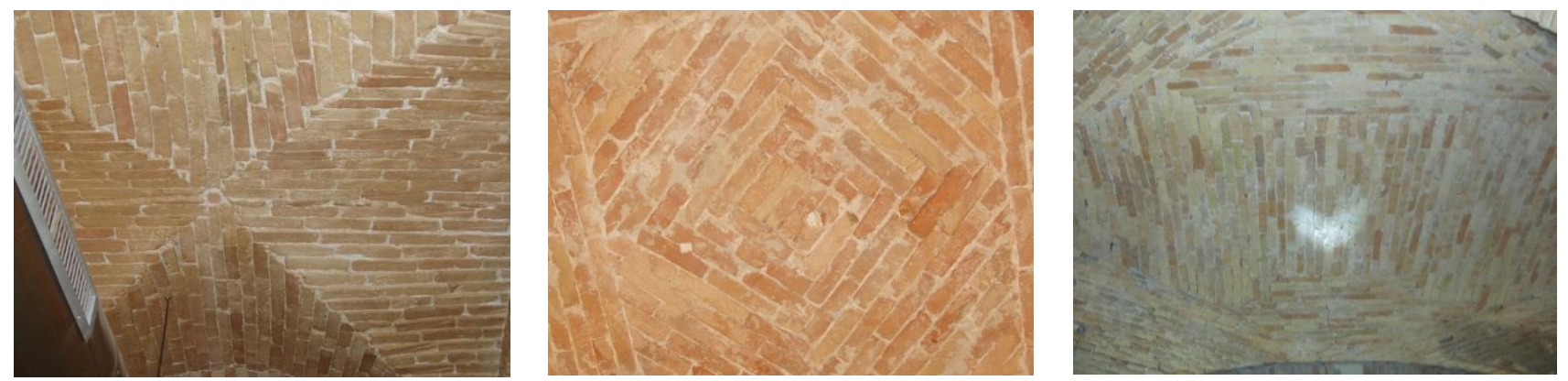

Fig. (5). Different textures of masonry vaults in the downtown of Cagliari (courtesy of Prof Cazzani, University of Cagliari, Italy). 


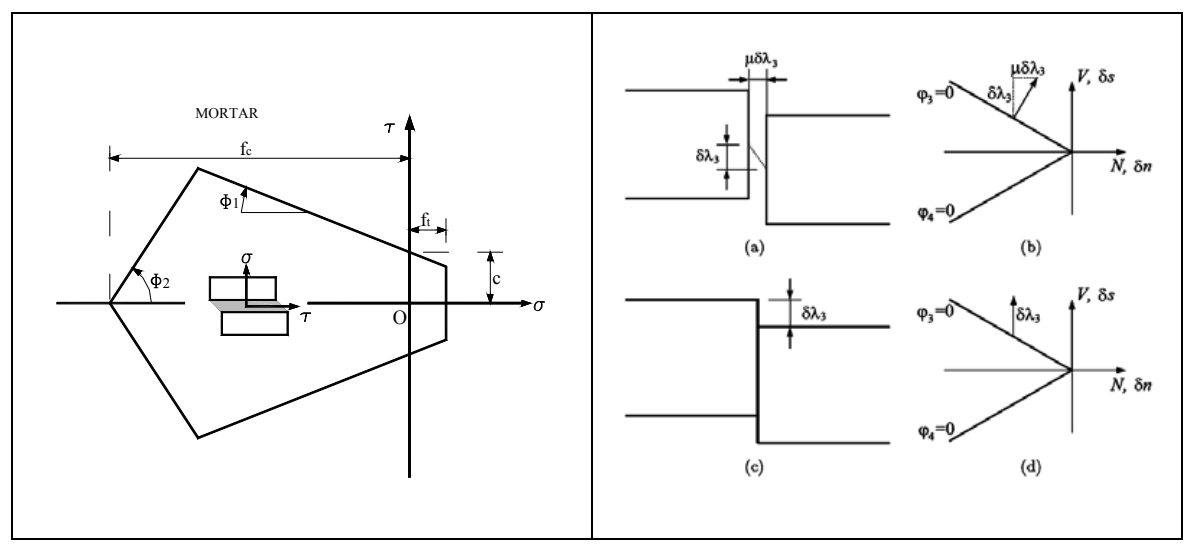

Fig. (6). a) Interface failure surface adopted for mortar joints by Sutcliffe et al. [29] and Milani et al. [26, 27], from [26]. b) Associated flow rule (top) with $\mu=\tan \Phi=\tan \psi$, and non-associated flow rule (below), with null dilatancy $(\tan \psi=0$ ). The yield criterion is represented as relationship between the normal $(\mathrm{N})$ and shear forces $(\mathrm{V})$, from [5].

be used straightforwardly. Standard formulations adopt a simple frictional Coulomb law characterized by a friction angle $\Phi$ at the contact interfaces. Applying the normality condition (or associated flow rule) leads, in this case, to a fixed dilatancy (normal separation between blocks) characterized by an angle $\psi$ necessarily equal to $\Phi$, where $\tan \psi$ is the ratio between normal and tangent deformation (Fig. 6b). In reality, no physical condition leads to this value, real dilatancy of masonry being variable and almost null in many cases.

A number of authors proposed different numerical methods (Livesley [33], Orduna \& Lourenço [23], Gilbert et al. [22], Tangaramvong and Tin-Loi [34]. The effects of friction on the static behavior of arch bridges has been discussed by Drosopoulos et al. [35], whereas the effect of friction on the stability of masonry vaults has been studied by D'Ayala and coworkers [36, 37], who assert that limit state analysis with finite friction allows to investigate two aspects of masonry vaults previously neglected: the possibility of sliding mechanisms between blocks and the importance of threedimensional stress fields in the equilibrium of complex vaults. Particularly the analysis has been able to show that for values of the coefficient of friction smaller than 0.5 , slid- ing can become a critical failure mode and further increases in thickness are necessary to re-establish equilibrium.

\subsubsection{Importance of the Overall Geometry for Achieving the Equilibrium}

Nowadays new laser scanner techniques are available for accurate geometric surveys of actual masonry vaults (Schueremans and Van Genechten [38]). Obviously, the evaluation of gravity loads and of their work in the kinematic limit analysis or of the thrust line in the static approach depends on the way the geometry is taken into account. For instance, an example of this effect can be appreciated by looking at the difference between the limit load multipliers evaluated by curved six-noded elements and by plane triangular elements, as shown in Fig. (7), in the case of a hemispherical dome [39-41].

Recentely, Carini \& Genna [42] for a particular case study (an old masonry vault subjected to compressive longitudinal loads in the Basilica Romana Minore di San Lorenzo in Verolanuova, Brescia) have emphasized the importance of accurately reproducing the actual geometry. For instance in their 3D non linear analysis, where the masonry is modeled

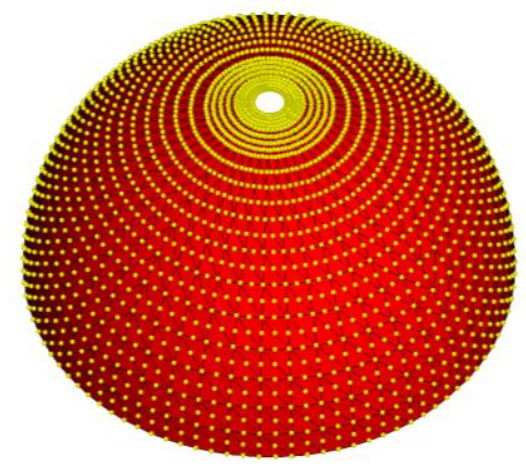

(a)

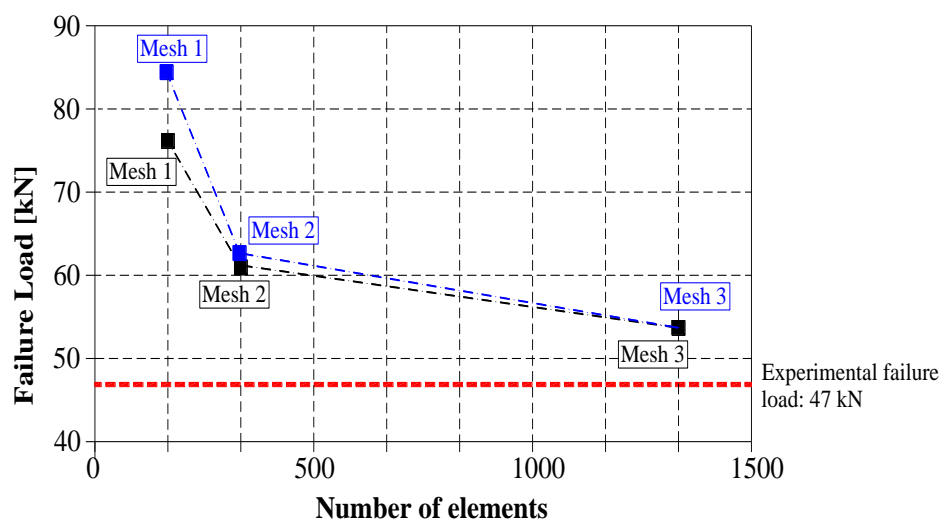

(b)

Fig. (7). Hemispherical dome analysed in [39-41]. (a) Refined discretization (Mesh 3):1344 elements and 2784 nodes. (b) Mesh dependence study (Black: six-noded curved elements. Blue: three-noded flat elements). 
as an elastic plastic material with Drucker Prager yield surface, the implementation of actual imperfections causes a reduction of the collapse load of about $65 \%$ (from 14.93 to $5.45 \mathrm{MN}$ ) with respect to the case with no imperfections. This gives a good evidence of the extreme importance of the correct definition of the actual geometry for this class of problems.

However, at least two additional factors must be taken into account in the analysis of masonry vaults, i.e. the effect induced by the presence of infill and the presence of preexisting crack patterns.

\subsubsection{Importance of Taking Into Account the Infill}

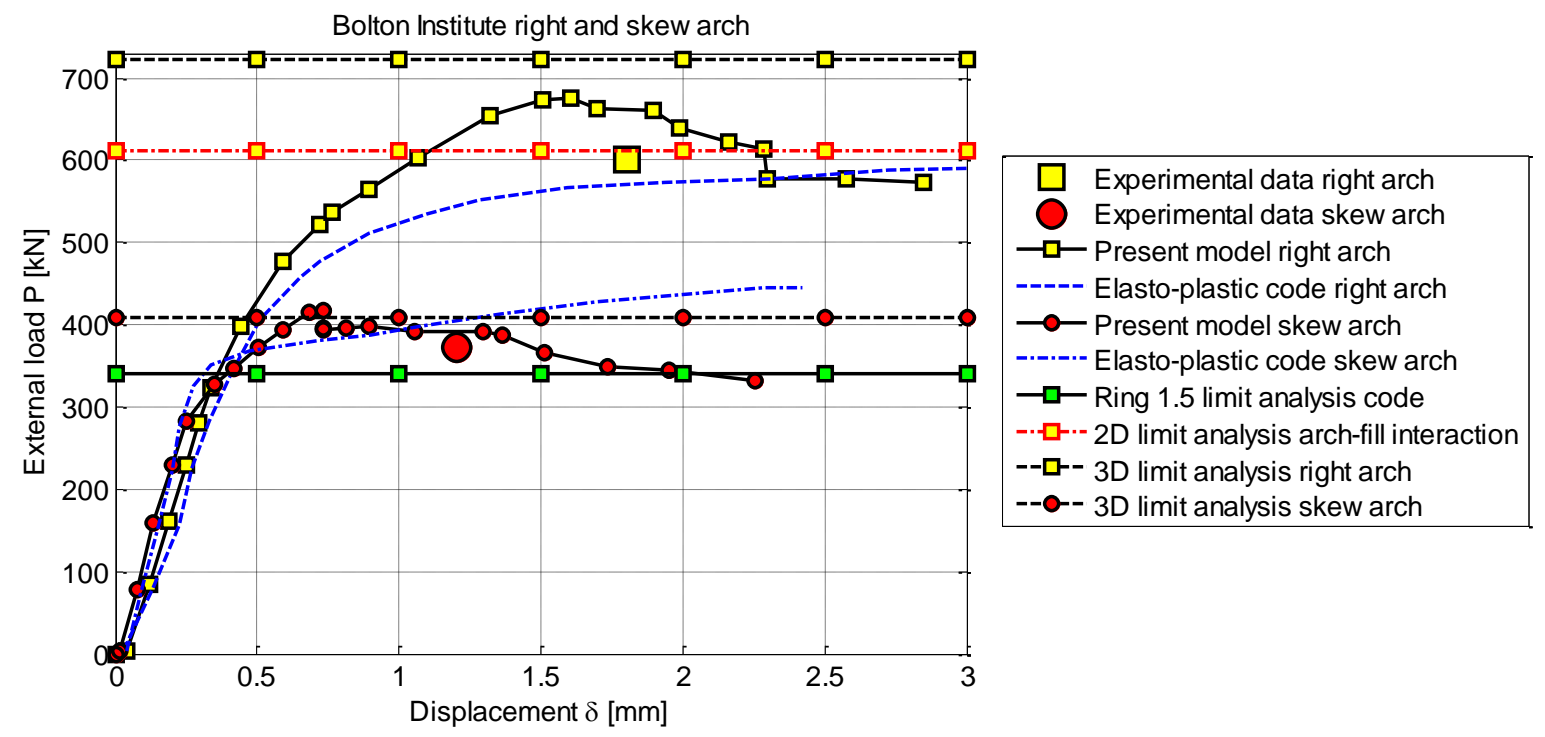

(a)

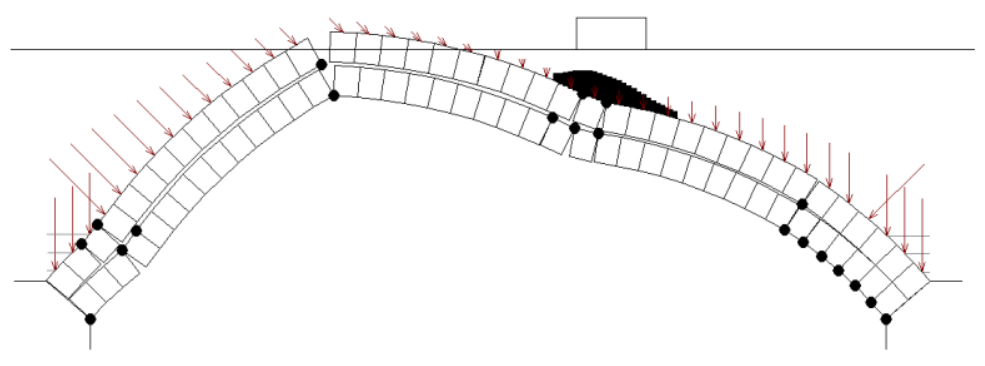

Infill stabilizing effect is particularly important for masonry arch bridges. A large amount of technical literature deals with masonry arch bridges [43-52] and the research in the field is at present very active, due also to the consistent number of railway masonry arch bridges that are still in service. In this context, the importance of taking into account the back fill has long been recognized. Recently Cavicchi and Gambarotta [50, 51] have rigorously investigated the role played by the backfill in the determination of the actual bearing capacity of 2D bridges and Milani \& Lourenço [43] have presented a 3D limit analysis study of a skew masonry arch bridge by taking into account transversal effects, Fig. (8).

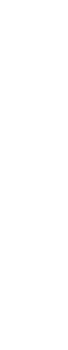

(b)

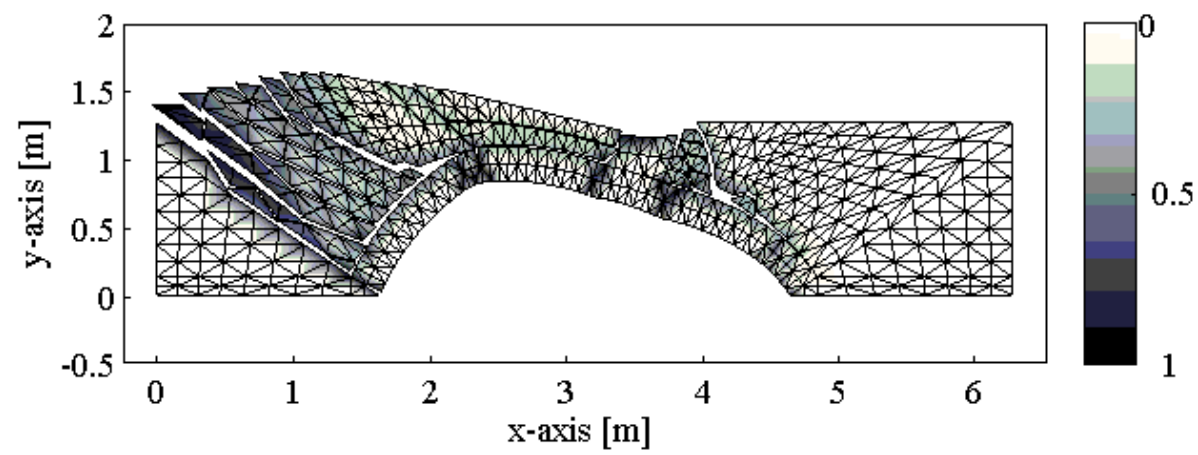

(c)

Fig. (8). (a) Vertical load-maximum vertical displacement curves obtained in [43]. In the figure experimental data available, collapse loads provided by Ring [52], 2D FE limit analysis with arch-fill interaction, 3D FE limit analysis and elastic-plastic FE models are also represented. (b) and (c) Deformed shape at collapse obtained by using Ring software [52] and the 2D limit analysis code proposed in [27] with arch-fill interaction. 


\subsubsection{Importance of Taking Into Account the Existing Cracks}

Existing masonry vaults present generally a diffused crack pattern due too many and mostly unknown factors (e.g. building sequence, settlement of foundations, seismic events, wrong consolidation works etc.). The crack pattern obviously affects the structural behavior and should be considered in the analysis. It can be observed that, at least in masonry vaults built with regular stones or solid clay bricks, the cracks are evident and clearly separated from each other, Fig. (9); moreover, treating cracks as distributed distortions appears still questionable. Despite the importance of the problem and its diffusion, a model suitable for the analysis of previously damaged vaults seems still missing.

\section{COMPUTATIONAL METHODS}

The recently developed computational methods can be classified into two broad categories: thrust network methods, subsection 3.1, based on the Static Theorem of limit analysis, and the Finite Element method, developed both for nonlinear incremental analysis, 3.2, and for limit analysis, 3.3.

\subsection{Thrust Network Methods (TNM)}

In order to extend thrust line to spatial structures, O'Dwyer [53] introduced the use of 3D funicular force networks defined in plan. His approach is limited to vertical loading and the layout of the networks is fixed in plan. Even though the fixed network in plan still inherently gives rise to conservative results, these $3 \mathrm{D}$ networks give a much better understanding of vaults than the previous simplified analysis that combines one-dimensional thrust line analyses. However, an important limitation of this method was the incapability to deal with the static indeterminacies in the horizontal

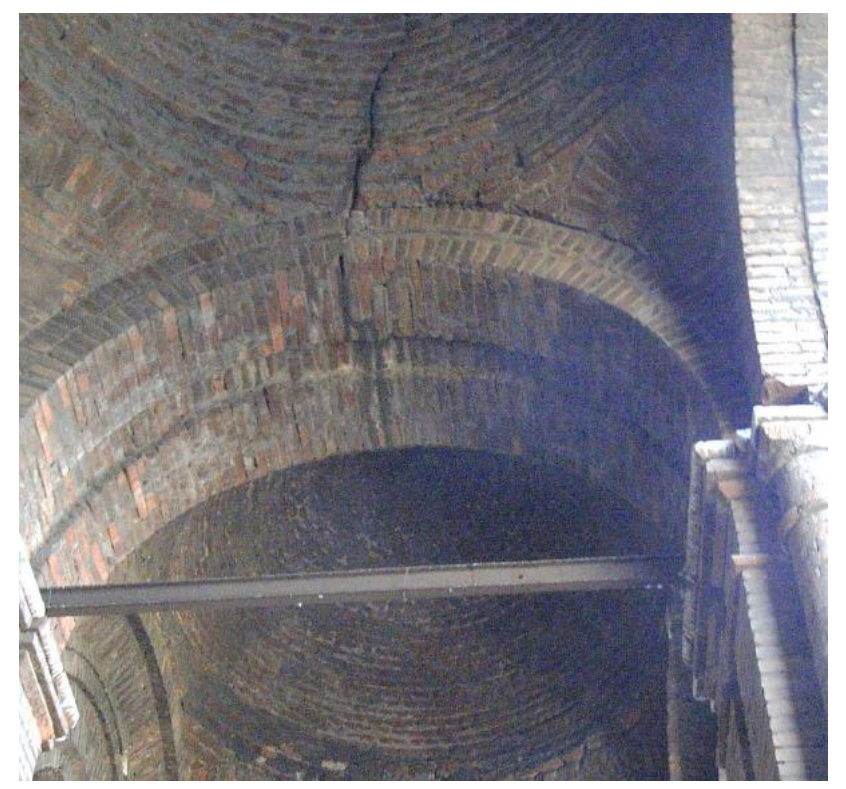

(a) equilibrium of networks with a fixed horizontal projection.

Building on O'Dwyer's seminal work, thrust network analysis (Block \& Co-workers [54-56]) addressed the first issue by introducing Maxwell reciprocal force diagrams, which describe the possible horizontal equilibria of compressive funicular networks, named thrust networks, under vertical loading. An important drawback of the original thrust networks framework, as presented in the abovementioned references, was the lack of a general algorithm and the necessity of the manual manipulation of the reciprocal force Diagrams. The extensions overcoming this limitation are discussed in Block \& Lachauer [56].

Another recent approach for 3D equilibrium analysis based on funicular networks and inspired to Gaudi's hanging models has been proposed by Andreu et al. in [57, 58]. The approach, in which general load cases could be easily included, is different from the previous one and the equilibrium solutions are not constrained to fixed horizontal projections.

A related approach to TNA for generating funicular networks in the presence of vertical loading has been proposed by Fraternali [59] as a specific 3D extension of the lumped stress method (Fraternali et al. [60]). It can be showed that their equilibrium conditions and global framework, separating horizontal and vertical equilibrium, was entirely equivalent to thrust network analysis, but in contrast, this approach, based on the discretization of Airy stress functions, presented some challenges with respect to singularities in the boundary conditions and loading, or discontinuities, such as cracks or openings, in the discretized equilibrium surfaces and the supports (Babilio et al. [61]). Very interesting and technically significant case studies have been recently discussed by Angelillo et al. in [62], Fig. (10).

Finally, an efficient solving algorithm, based on thrust

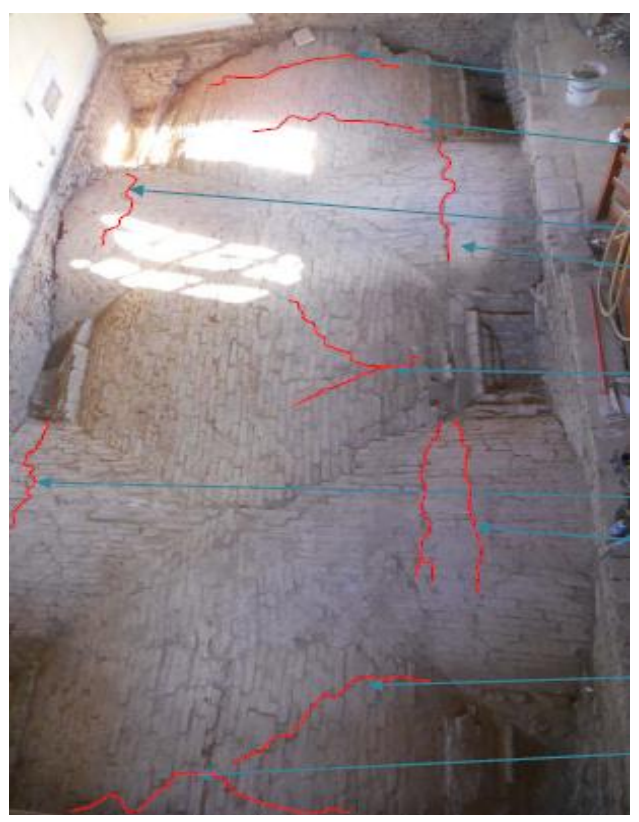

(b)

Fig. (9). (a) Porch vaults of the church of S. Francisco del Baron in Valparaiso (Chile) damaged by old seismic events. (b) extrados of Fornasini tower vaults in Poggio Renatico (Italy) damaged by 2012 Emilia Earthquake. 


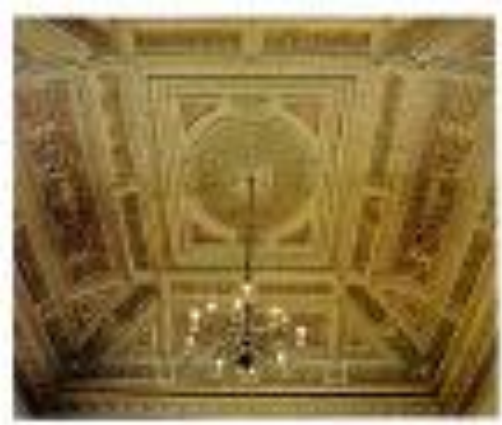

(a)

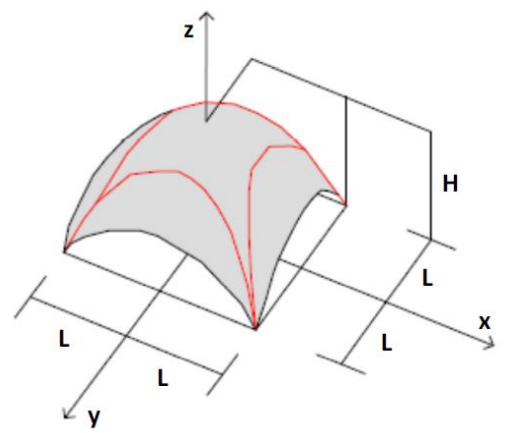

(b)

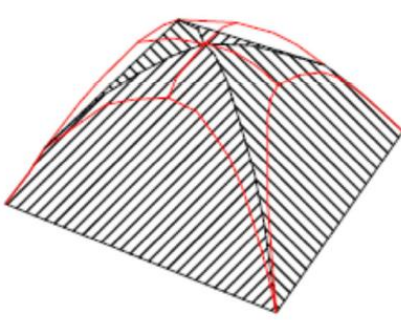

(c)

Fig. (10). (a) Cloister vault, "Soffitto Verde", in "palazzo del Pozzo della Cisterna", Torino. Parabolic shape of the thrust membrane (b) and comparison with the intrados surface of the cloister vault $(\mathbf{c})$. A reduced portion of the parabolic shape inside the masonry is shown in (b) and (c).

networks and the lumped stress method, has been presented by Vouga et al. [63] to find particular best-fit solutions to target surfaces, but their method is unable to capture typical sharp features of Gothic masonry vaults, such as creases along ribs. Convergence issues also have still to be cleared for the thrust network methods.

A different approach based on a selection of membrane stress surfaces and obeying equilibrium and a no tension masonry constitutive equation has been recently presented by Baratta and Corbi $[64,65]$. The problem is expressed in terms of a suitably defined stress function allowing some simplification. The solution is then sought by using an energy approach. In general, it is also proved that under gravitational loads the equilibrium of the vault implies its admissibility. This result is quite significant because it explains why it is possible to build up masonry vaults by simply hypothesizing a resistant shape under the assigned loads.

\subsection{FE Methods: Incremental Nonlinear Analyses}

Unsurprisingly, ancient masonry vaults have been studied since long time ago by using the most advanced tools available for structural assessment. The first researches on the static behavior of these structures began in the late 80 s of the last century and the two older authors of this note (Alessandri and Tralli), in those days at the University of Florence, want to remember the pioneering studies of the Brunelleschi Dome by Chiarugi et al. [66] and the criticisms by Di Pasquale. In any case, the reader is referred to Roca et al. [5] for a more complete report on the subject.

Having regard to the studies published since 2000, it is possible to observe that a number of FE commercial programs are often used in the technical literature to model masonry vaults. As a matter of fact, all such programs are FE codes developed to study steel or concrete structures by means of a load increment strategy and modified values of the initial stiffness of the elastic element; cracks are taken into account as a kind of smeared distortions. Usually, elastic plastic constitutive equations with associate flow rule and different yield surfaces are employed for steel structures, whereas much more complex elastic plastic damaging constitutive models have been developed for concrete. The heterogeneity of masonry is not accounted for and isotropic behavior either in the elastic field or at collapse is generally assumed. However it is worth noting that these techniques of analysis turn out to be adequate if combined with proper engineering reasoning.

By way of example, with no claim to be exhaustive, the Authors mention that: Carini and Genna [42], Bagicalupo et al. [21] and Audenaert et al. [49] used ANSYS by assuming for masonry some elastic-plastic material models (either Drucker-Prager or Willam-Wranke with low tension strength); D'Ayala \& Tomasoni [37] used Algor V21 with contact elements, Theodossopoulos et al. [67] employed Abaqus, Creazza and co-workers [68, 69] Midas with a so called concrete model, etc.

To the Authors' knowledge, only two programs, namely DIANA by TNO Delft [70] and NOSA CNUCE by CNR Pisa [71], contain specific software developed for studying masonry curved structures.

The first one, which refers to the Ph.D. thesis by Lourenço at Delft University, is based on an accurate modeling of the masonry mechanical behaviour which requires a thorough experimental description of the material. The reader is referred to [70] for a more comprehensive discussion on these issues. A basic notion is introduced, named softening, to represent the gradual decrease of the mechanical resistance under a continuous increase of the deformation imposed on a material specimen or a structure. DIANA recovers, if necessary, the mesh independence by some numerical procedures derived from brittle fracture Mechanics and allows using contact-gap elements. The program has been satisfactorily used by a number of researchers to analyze masonry vaults and complex historical masonry structures. Pizzolato et al. [72] for instance studied the vaults of the "Tre Ponti" bridge in Comacchio, Italy, see Fig. (11).

The second one is based on the constitutive assumption of no tension material. The main hypotheses are, as previously quoted, that masonry behaves as a nonlinear hyperelastic (homogeneous isotropic) no tension material, i.e. with zero tensile strength and infinite compressive strength, and the cracks are dealt as distributed distortions. The infinitesimal strain $\boldsymbol{E}$ is the sum of an elastic part and a positive semidefinite fracture part: in symbols, $\boldsymbol{E}_{\boldsymbol{B}} \boldsymbol{E}_{\boldsymbol{e}}+\boldsymbol{E}_{\boldsymbol{f}}$. Moreover, the Cauchy stress $\boldsymbol{T}$, negative semi-definite and orthogonal to $\boldsymbol{E}_{f}$, depends linearly and isotropically on $\boldsymbol{E}_{\boldsymbol{e}}$. $\boldsymbol{E}_{\boldsymbol{f}}$ is called the frac- 


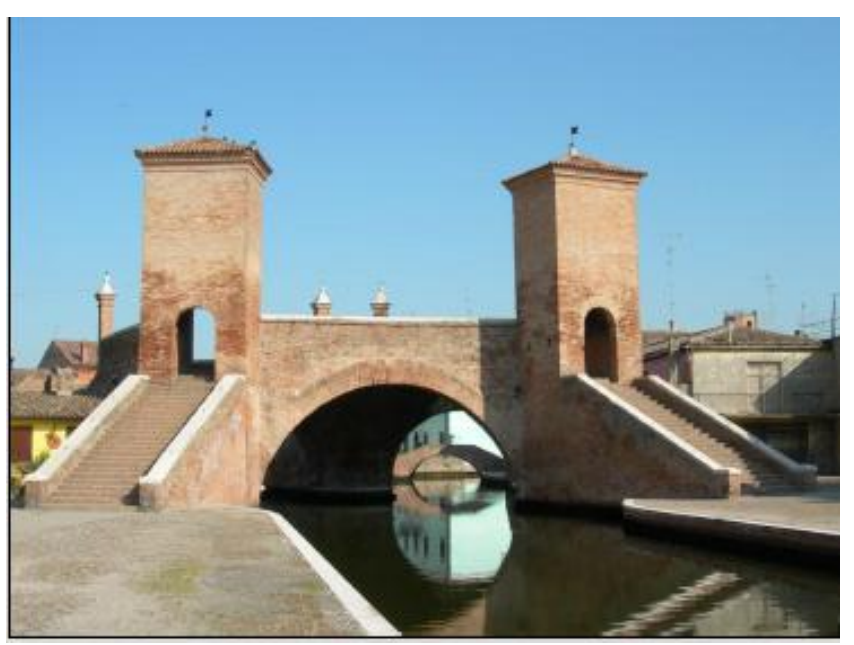

(a)

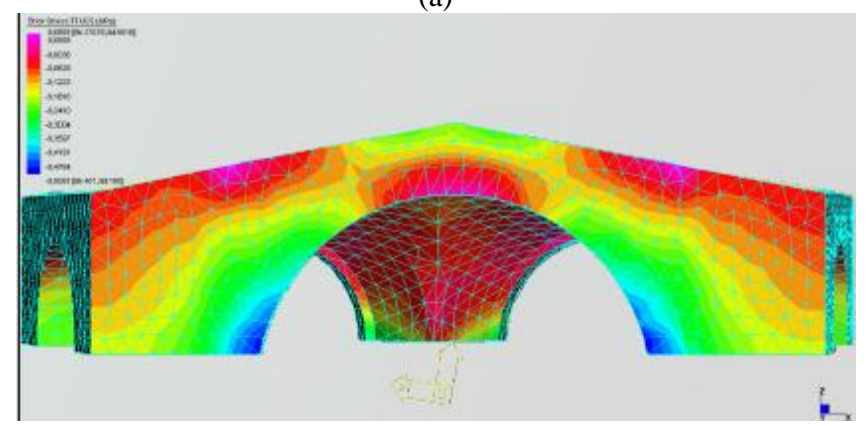

(c)

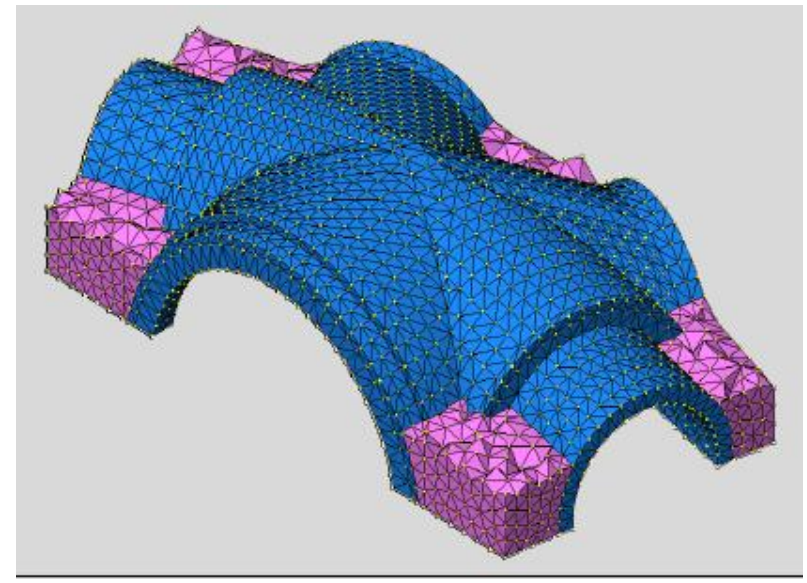

(b)

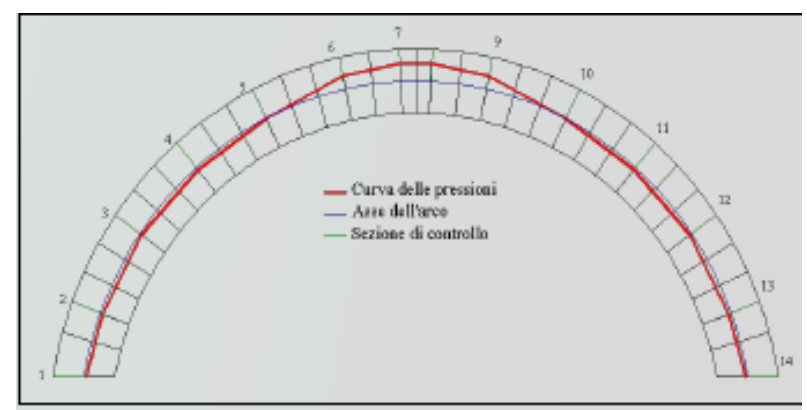

(d)

Fig. (11). (a) The Tre Ponti bridge in Comacchio Italy, (b) 3D model proposed in [72], (c) vertical normal stress patch, d) thrust line in the arch above Pallotta canal.

ture strain because it is responsible for the occurrence of cracks in the regions where it has non null values [73].

The equilibrium problem of masonry vaults and domes is solved by using non conforming quadrilateral eight-node shell elements based on the Love-Kirchhoff hypothesis (Nagtegaal \& Slater [74]). In the search for the thrust surface a (non unique) maximum modulus eccentricity surface is evaluated in an original and elegant way, see Fig. (12).

\subsection{FE Methods: Limit Analysis and Incremental Anal- yses by Rigid Elements}

The limit analysis theory of classical plasticity [75] is based on the following basic assumptions:

- the structure is made of rigid plastic material with infinite ductility and associate flow rule for which the postulate of maximum plastic dissipation holds;

- the deformed configuration can be considered coincident with the initial one in writing the equilibrium equations.

As previously said, both the upper bound and lower bound theorem, after the discretization of the structure, can be cast in the form of two dual Linear Programming (LP) problems. These theorems can be applied to the no tension case [8], where the principal stresses are assumed to be nonpositive; however some computational problems occur:
- For instance the null state (the origin of the axes) lies on the border of the yield locus; as a consequence, a no tension structure in the absence of loads is outside the domain of feasibility and therefore, for instance, the first phase of the Dantzig simplex method fails as a set of algorithms for interior points. More realistic criteria can be employed where a very low tensile strength is generally assumed for masonry, but the convergence to the no tension solution has not to be proved.

- Moreover, if friction is taken into account, the normality is lost and the flow rule is not associate; in this case, as is well known, the limit analysis theorems do not hold and LP methods cannot be used straightforwardly.

However other important aspects discussed in Section 2, and generally neglected can be considered in an efficient way, such as:

- Heterogeneity and anisotropy of masonry material through a homogenization procedure [26, 27, 39-41];

- The infill can be taken into account $[43,50,51]$;

- Discrete and realistic crack patterns can be both taken into account and considered.

Homogenization consists in extracting a representative element of volume (REV) which generates the whole structure by repetition, in solving a boundary value problem on the REV and in replacing the assembly of bricks and mortar at a structural level with a fictitious orthotropic equivalent 


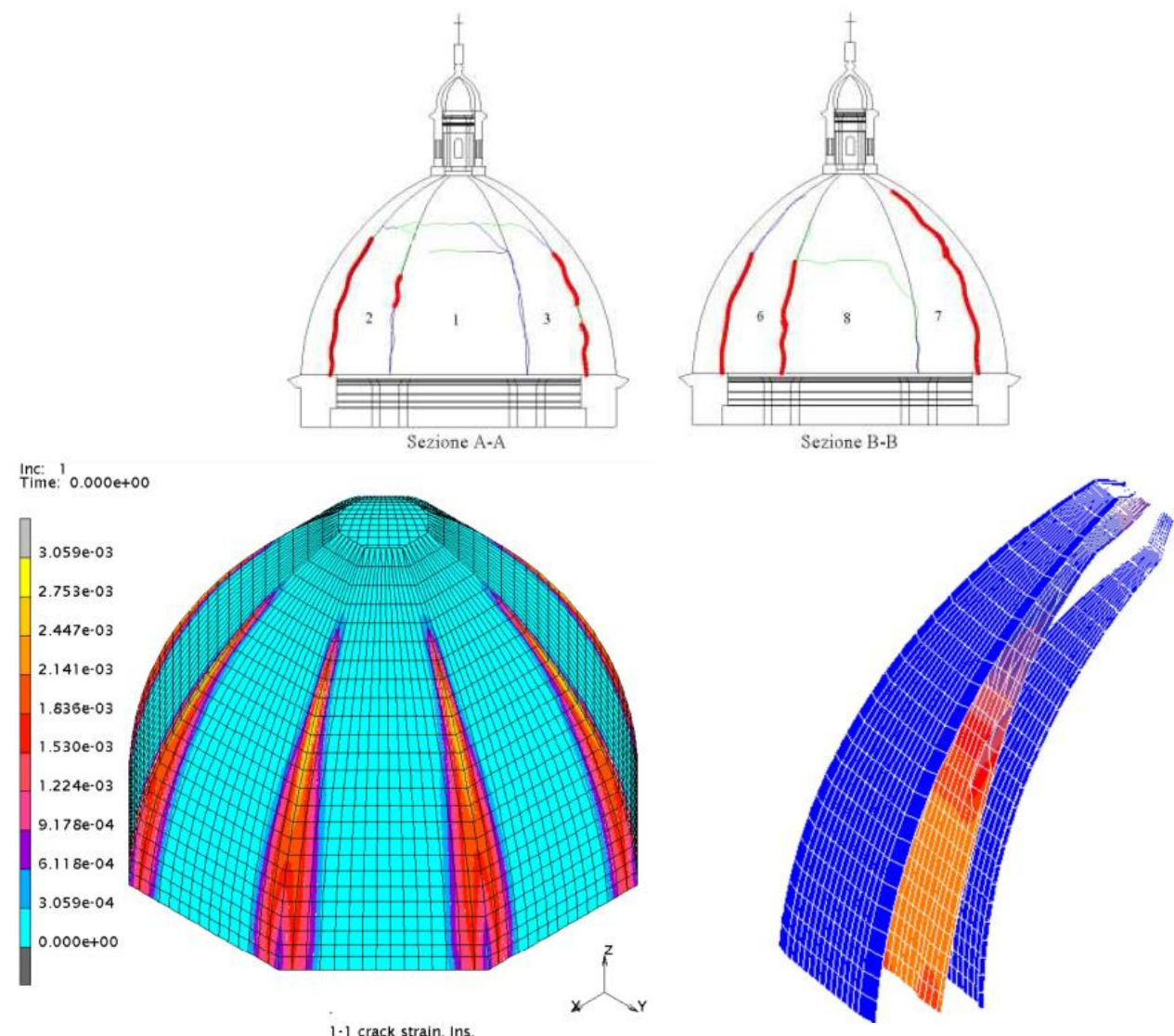

Fig. (12). The dome of the church of Santa Maria Maddalena in Morano Calabro from analyses reported in [73]. a) Sections A-A and B-B cracks distribution at the intrados, b) Fractures strains of the dome subjected to its own weight, c) Maximum modulus eccentricity in a web.
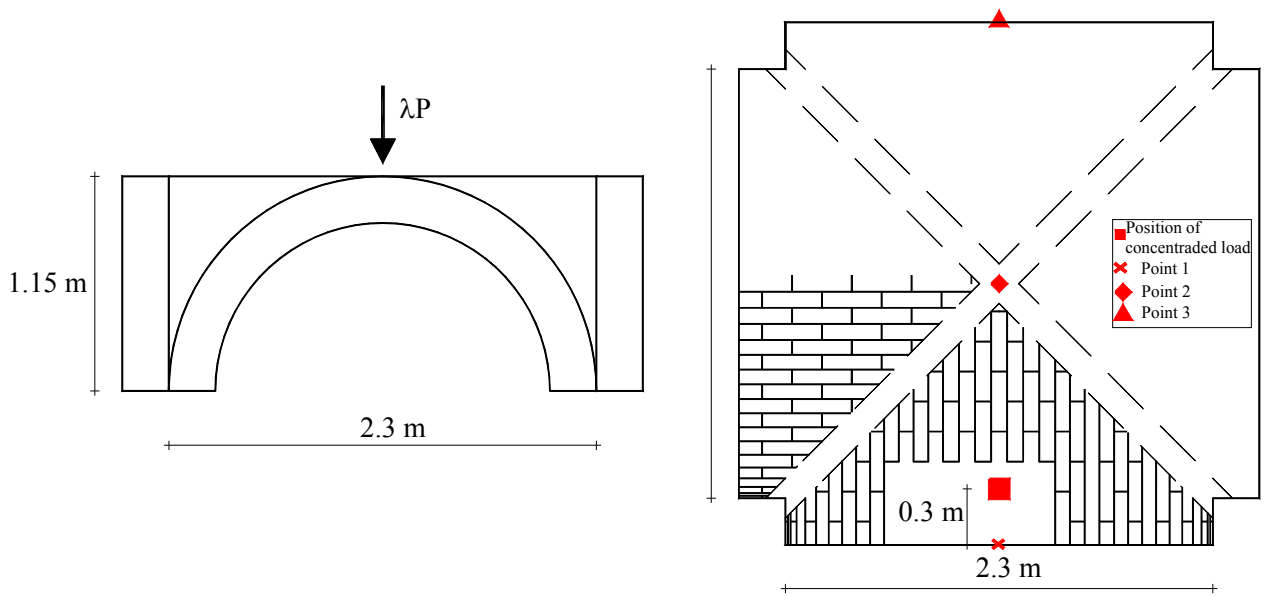

Fig. (13). Ribbed cross vault. Geometry and loading condition, from [39].

material with mechanical properties evaluated at a cell level. The homogenization theory has a sound mathematical basis when dealing with elastic, elastic plastic or rigid-plastic $[26,27,40,76,77]$ constitutive equations. However, in the present case often it cannot be used rigorously, due both to the impossibility of identifying a cell.

which generates the double curvature structure by repetition and to the assumption of non-linear material properties with softening. For this reason, simplified kinematic procedures have to be attempted. In a number of papers by the Authors, a homogenization approach is used: in particular, the vault is modeled by means of an orthotropic homogenized material obtained with a mesoscopic approach similar to the one proposed by Milani et al. [26, 27], whereas the infill (if present) may eventually be modeled by means of an isotropic MohrCoulomb material with tension cutoff and softening, Milani \& Lourenço [43].

To limit the computational effort, in the framework of limit analysis, it is needed to model the structures by adopting rigid elements and homogenized interfaces. Both three- 
noded rigid curved shell elements [39] and six-noded rigid infinitely resistant wedge elements $[40,41]$ have been proposed, where also FRP reinforcement may be also considered.

In these aforementioned papers, the whole deformation is concentrated exclusively at the interfaces (modeled by assuming either an isotropic frictional material, as for the infill, or by means of a homogenized orthotropic material as in the case of masonry), thus requiring a very limited number of optimization variables to be performed. Fig. (13) shows a ribbed cross vault previously numerically modeled by Creazza et al. in [69] and experimentally tested by Foraboschi and co-workers [78, 79] before and after the application of FRP reinforcements. The results obtained by the limit analysis proposed in [40, 41] are summarized in Fig. (14).

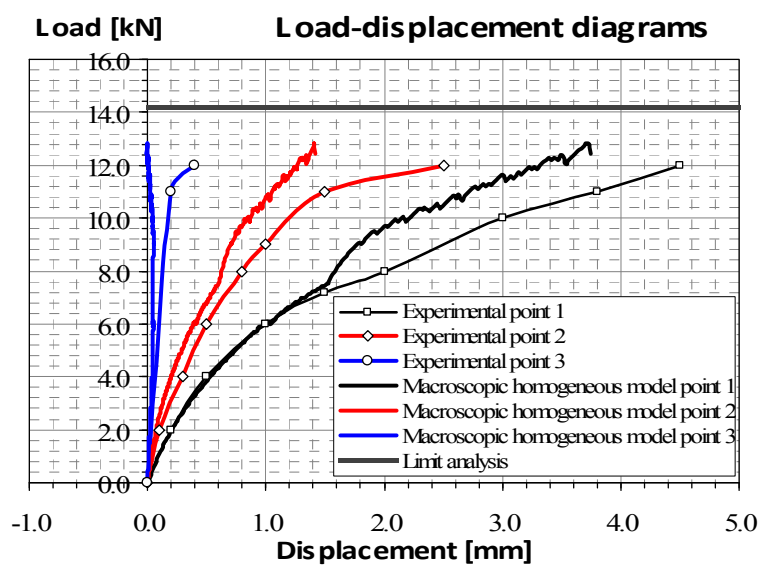

(a)
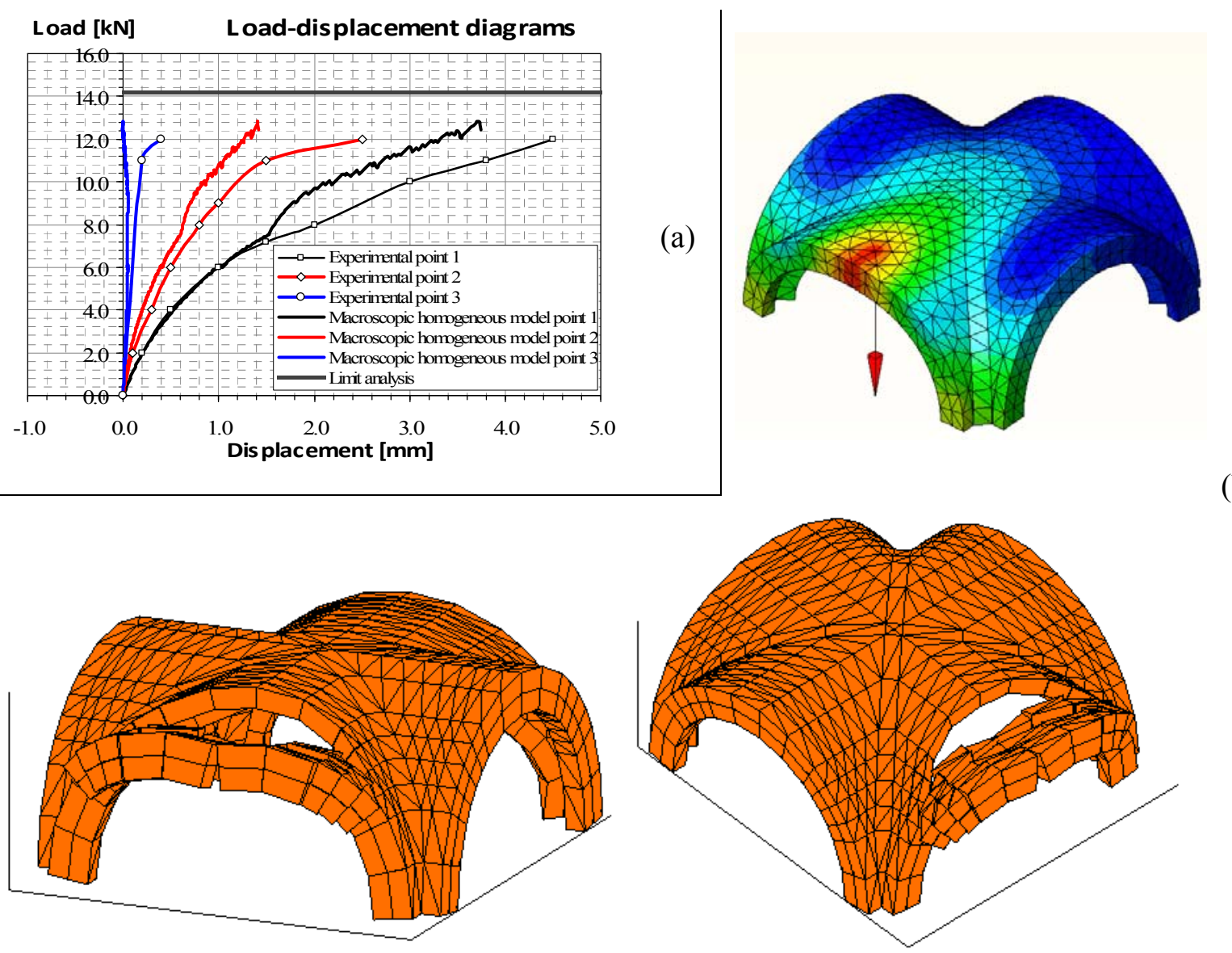

(b)
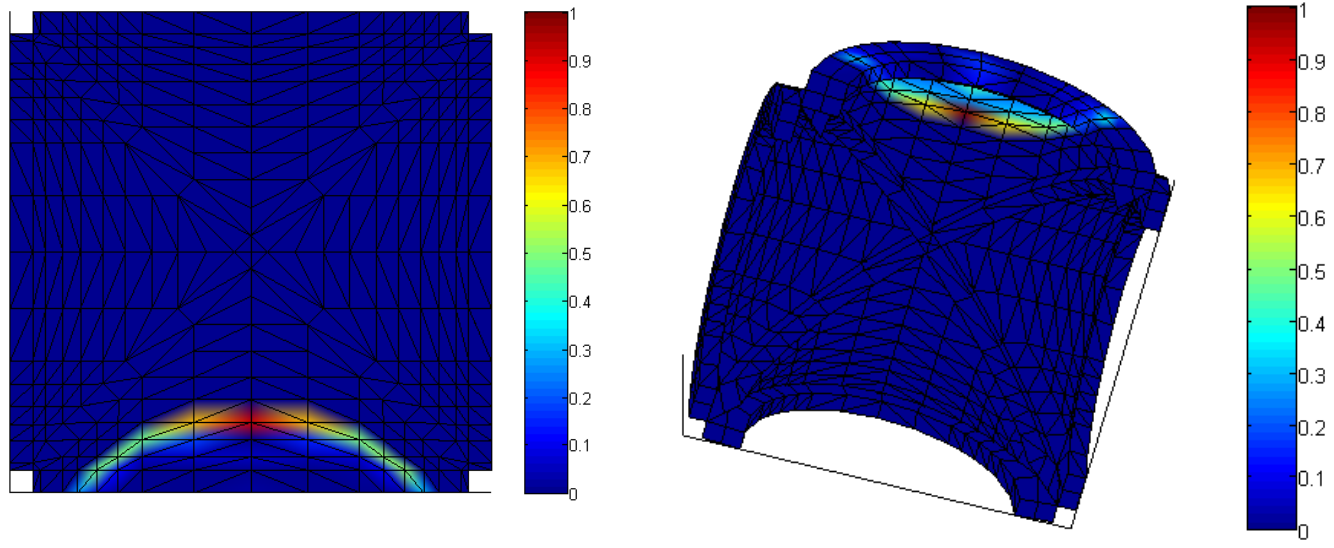

(c)

Fig. (14). Ribbed cross vault studied in [40, 41]. (a) Comparison among collapse loads provided by experimentation, limit analysis and nonlinear FE code. (b) Deformed shapes at collapse from limit analysis and non-linear FE code. (c) Normalized plastic dissipation patch obtained from limit analysis (left: top view. Right: bottom view). 
However, it is worth noting that a well-known major drawback of such "rigid plastic" approaches is the inability to provide displacements during the deformation process, an important information required instead by some national codes of practice (e.g. Italian NTC2008 [80]), where nonlinear incremental analyses (pushover) are suggested.

To circumvent this major limitation, a 3D model for the evaluation of the non-linear incremental behavior of masonry double curvature structures has been recently presented in Milani \& Tralli [81]. In this model, the heterogeneous assembly of blocks is replaced by a macroscopically equivalent homogeneous non-linear material. At the meso-scale a curved running bond representative element of volume (REV), formed of a central block interconnected with its six neighbors, is discretized by means of a few six-noded rigid wedge elements and rectangular interfaces. Non linearity is concentrated exclusively in the joints modeled as interfaces exhibiting a frictional behavior with limited tensile and compressive strength and softening. The macroscopic homogenous masonry behavior is then evaluated in the REV by imposing separately increasing internal actions (in-plane membrane actions, meridian and parallel bending, torsion and out-of-plane shear). This simplified approach allows estimating heuristically the macroscopic stress-strain behavior of masonry at the meso-scale. The non-linear behavior so obtained is then implemented at a structural level in a novel FE non-linear code which relies on an assembly of rigid infinitely resistant six-noded wedge elements and non-linear interfaces and exhibits deterioration of the mechanical properties. Several numerical examples are taken into account with reference to different typologies of masonry vaults. In Fig. (15a), for instance, a cloister vault experimentally tested in $[78,79]$ is considered. Results provided in Milani and Tralli [81] are presented in Fig. (15b) and Fig. (16). To fully assess numerical results additional non-linear FE analyses were conducted in [81]. In particular, a simplified model was proposed: it consists in performing, at a structural level, a preliminary limit analysis - which allows identifying the failure mechanism - and subsequently in modeling masonry with elastic elements and non-linear interfaces placed only in correspondence of or near the cracks through which the failure mechanism provided by limit analysis is manifested.

\section{CONCLUSION}

In this paper the authors have reviewed some methods and models, now available in the technical literature and commonly used in the analysis of masonry vaults up to their collapse, by highlighting advantages and drawbacks of each of them. As is known, when masonry is the constituent material, the resistant structure is not necessarily coincident with the whole masonry construction but it is usually only a part of it, hidden inside, and changes according to the different external loads and constraint conditions. From a geometrical point of view masonry vaults are able to withstand external loads basically by virtue of their shape, and in this way it is possible to state that form and structure are in such cases coincident. All methods adopted to describe the mechanical behavior of masonry structures, in order to be reliable, must take into account the distinctive aspects of masonry, namely the scarce (or zero) tensile strength, the good resistance in compression and the occurrence of failure mechanisms through rotation-translation of rigid macro-blocks. Classic no-tension material models in some cases provide closedform solutions, within a rather elegant formulation, by assuming a zero-resistance in tension, infinite strength in compression and an isotropic behavior. More sophisticated models -nearly always based on FEM- allow nowadays to deal with anisotropy induced by texture, small tensile strength and softening, but they still require at the same time a large computational effort. Traditionally, Limit Analysis has proved to be the most effective Method for a fast and reliable evaluation of the load bearing capacity of vaulted masonry structures: classic lower and upper bound theorems recall respectively the concepts of equilibrium and occurrence of failure mechanisms with rigid elements. The so-called Thrust Network Method is influenced by the lower bound theorem, whereas the set of approaches based on FE Limit Analysis with infinitely resistant elements and concentrated dissipation usually takes inspiration from the upper bound theorem. An alternative to Limit Analysis is represented by traditional FEM combined with either elastic-plastic or damaging models with softening, commonly used for other materials but recently adapted also to masonry. They are able to provide a large set of output numerical information but further studies are still needed to ensure their proper application.

\section{CONFLICT OF INTEREST}

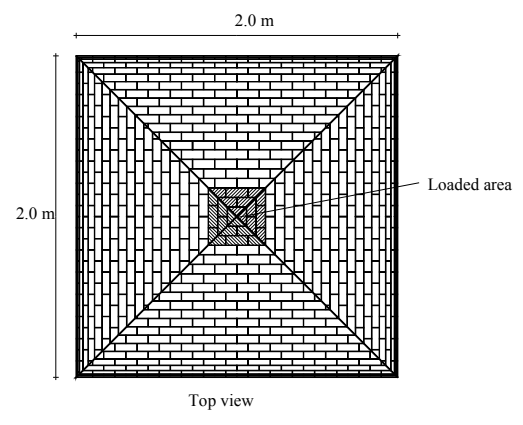

(a)
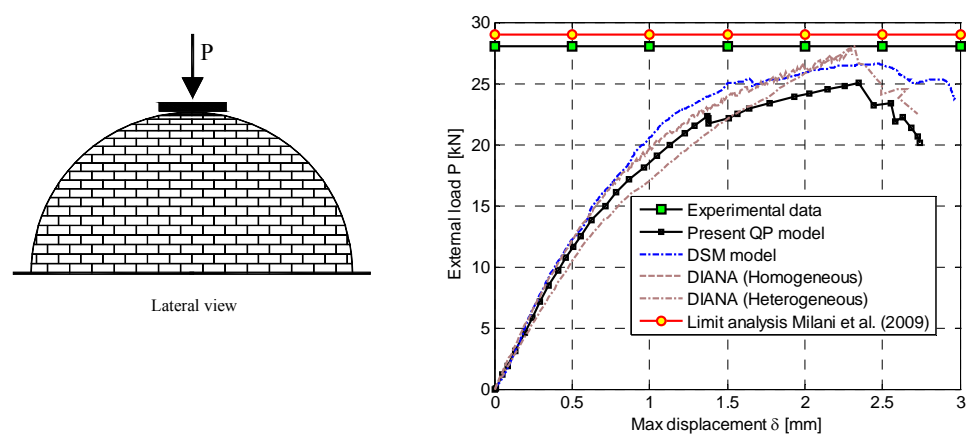

(b)

Fig. (15). Cloister vault analysed in [81]. a) Geometry and loading conditions. b) Comparison among load-displacement curves or collapse loads provided by experimentation, limit analysis and non-linear FE code. 


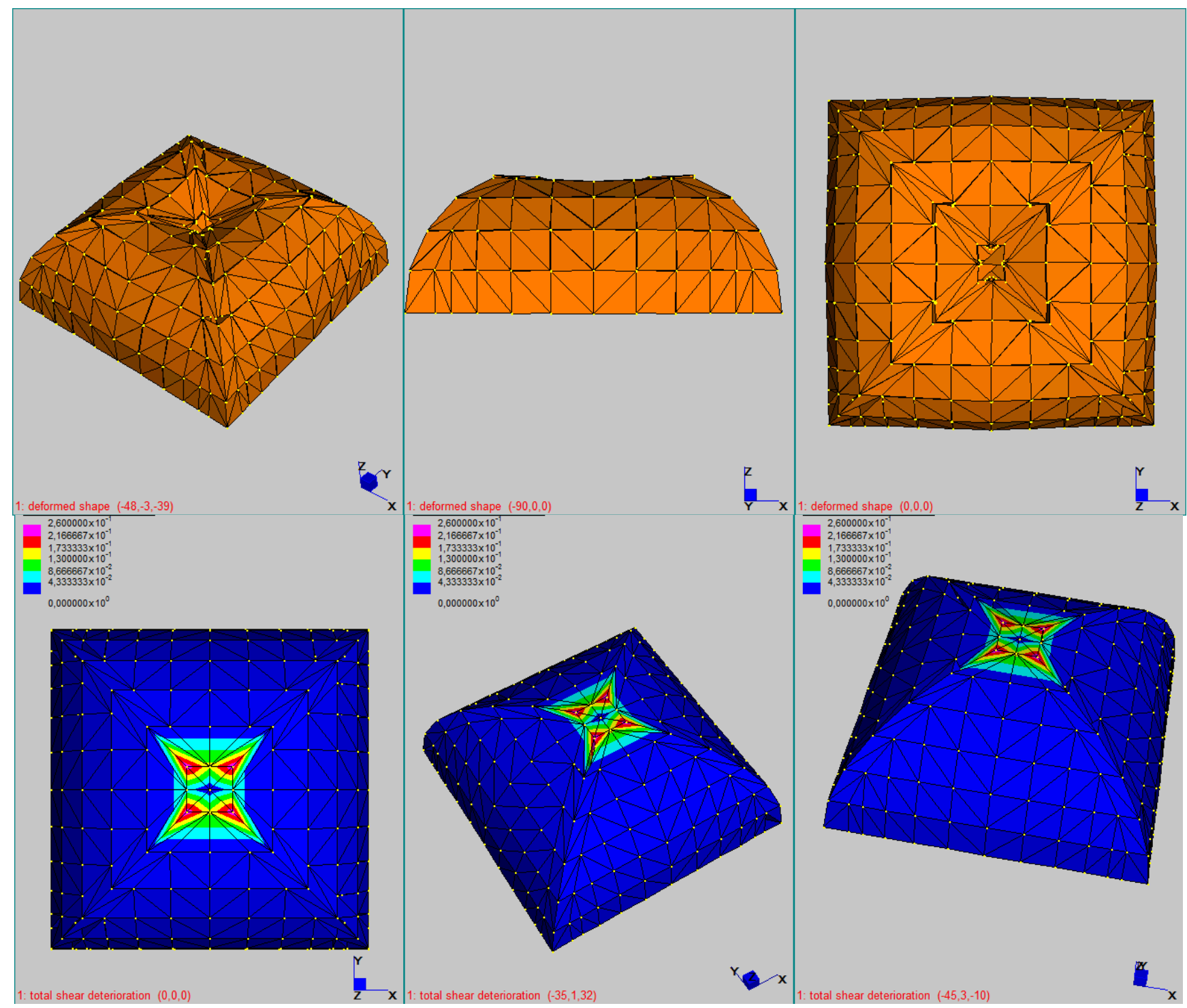

Fig. (16). Cloister vault. Deformed shapes at peak and damage patch provided by the non-linear code proposed in [81].

The authors confirm that this article content has no conflict of interest.

\section{ACKNOWLEDGEMENTS}

Declared none.

\section{REFERENCES}

[1] ICOMOS. Recommendations for the analysis, conservation and structural restoration of architectural heritage. 2001.

[2] Italian Guidelines for Cultural Heritage Buildings. Linee guida per la valutazione e la riduzione del rischio sismico del patrimonio culturale, Ministero per i beni e le attività culturali MiBAC, Italy 2011.

[3] Giuffrè, Letture sulla meccanica delle murature storiche (in Italian). Kappa Rome (Italy), 1990.

[4] S. Di Pasquale, L'arte di costruire (in Italian). Marsilio Venice (Italy), 1996.

[5] P. Roca, M. Cervera, G. Gariup, and L. Pelà, "Structural analysis of masonry historical constructions. classical and advanced approaches”, Arch. Comput. Method. Eng., vol. 17, pp. 299-325, 2010.
[6] J. Heyman, Equilibrium of shell structures. Oxford, Oxford University Press (UK), 1977.

[7] S. Di Pasquale, "New trends in the analysis of masonry structures", Meccanica, vol. 27, pp. 173-184, 1992.

[8] G. Del Piero, "Limit analysis and no-tension materials", Int. J. Plasticity, vol. 14(1-3), pp. 259-271, 1998.

[9] M. Giaquinta and E. Giusti, "Researches on the equilibrium of masonry structures", Arch. Rational Mech. Analy., vol. 88, pp. 359392, 1985.

[10] G. Anzelotti, "Elasticity with unilateral constraints on the stress," in International workshop on Integral Functionals in Calculus of Variations, Suppl. Rend. Circolo Matematico di Palermo s.2 (15), 1987, pp. 135-141.

[11] E. Benvenuto, An introduction to the history of structural mechanics. Springer-Verlag Berlin (Germany), 1991.

[12] S. Huerta, "Mechanics of masonry vaults: the equilibrium approach," In Structural Analysis of Historical Constructions, Guimarães (Portugal), 2001.

[13] S. Huerta, "The analysis of masonry architecture: A historical approach", Arch. Sci. Rev., vol. 51, no. 4, pp. 297-328, 2008.

[14] M. Como, Statics of historic masonry constructions. SpringerVerlag Berlin (Germany), 2013. 
[15] J. Heyman, "The stone skeleton", Int. J. Solids Struct., vol. 2, no. 2, pp. 249-256, 1966.

[16] A.J.S. Pippard and E.R.J. Ashby, "An experimental study of the voissour arch", J. Inst. Civ. Eng., vol. 10, pp. 383-403, 1936.

[17] A.J.S. Pippard, "The approximate estimation of safe loads on masonry bridges", Civil Eng. War: Inst. Civ. Eng., vol. 1, pp. 365-371, 1946.

[18] Kooharian, "Limit analysis of voussoir (segmental) and concrete arches", J. Am. Concrete Inst., vol. 49, no. 12, pp. 317-328, 1952.

[19] J. Heyman, The stone skeleton: Structural engineering of masonry architecture. Cambridge University Press (UK), 1995.

[20] P.J. Fanning and T.E. Boothby, "Three dimensional modelling and full scale testing of stone arch bridges", Comput. Struct., vol. 79, no. 29-30, pp. 2645-2662, 2001.

[21] Bagicalupo, A. Brencich, and L. Gambarotta, "A simplified assessment of the dome and drum of the Basilica of S. Maria Assunta in Carignano in Genoa", Eng. Struct., vol. 56, pp. 749-765, 2013.

[22] M. Gilbert, C. Casapulla, and H.M. Ahmed, "Limit analysis of masonry block structures with non-associative frictional joints using linear programming", Comput. Struct., vol. 84, pp. 873-887, 2006.

[23] Orduña and P.B. Lourenço, "Three-dimensional limit analysis of rigid blocks assemblages. Part I: Torsion failure on frictional joints and limit analysis formulation", Int. J. Solids Struct., vol. 42, no. 18-19, pp. 5140-5160, 2005.

[24] A.W. Page, "The biaxial compressive strength of brick masonry", Proc. Instit. Civil Eng., Part 2, vol. 71, pp. 893-906, September 1981.

[25] M. Dhanasekar, A.W. Page, and P.W. Kleeman, "The failure of brick masonry under biaxial stresses", Proc. Instit. Civil Eng., Part 2, vol. 79, pp. 295-313, June 1985.

[26] G. Milani, P.B. Lourenço, and A. Tralli, "Homogenised limit analysis of masonry walls, Part I: failure surfaces", Comput. Struct., vol. 84, pp. 166-180, 2006.

[27] G. Milani, P.B. Lourenço, and A. Tralli, "Homogenised limit analysis of masonry walls, Part II: structural examples", Comput. Struct., vol. 84, no. 3-4, pp. 181-195, 2006.

[28] P.B. Lourenço and J. Rots, "A multi-surface interface model for the analysis of masonry structures”, J. Eng. Mech. ASCE, vol. 123, no. 7, pp. 660-668, 1997.

[29] D.J. Sutcliffe, H.S. Yu, and A.W. Page, "Lower bound limit analysis of unreinforced masonry shear walls", Comp. Struct., vol. 79, pp. 1295-1312, 2001.

[30] G. Vasconcelos and P.B. Lourenço, "Assessment of the in-plane shear strength of stone masonry walls by simplified models," $5^{\text {th }}$ International Conference of Structural Analysis of Historical Construction, New Delhi, 2006.

[31] D. Radenkovic, "Théorèmes limites pour un materiau de Coulomb a dilatation non standardise", Comptes Rendue Académie Sciences Paris, vol. 252, pp. 4103-4104, 1961.

[32] J. Salençon, Application of the theory of plasticity in soil mechanics, John Wiley \& Sons (USA), 1977.

[33] R.K. Livesley, "Limit analysis of structures formed from rigid blocks", International J. Num. Methods Eng., vol. 12, pp. 1853$1871,1978$.

[34] S. Tangaramvong and F. Tin-Loi, "An FE-MPEC approach for limit load evaluation in the presence of contact and displacement constraints", Int. J. Solids Struct., vol. 91, no. 5, pp 491-515, 2012.

[35] G.A. Drosopoulos, G.E. Stavroulakis, and C.V. Massalas, "Limit analysis of a single span masonry bridge with unilateral frictional contact interfaces", Eng. Struct., vol. 28, no. 13, pp. 1864-1873, 2006.

[36] D. D'Ayala, and C. Casapulla, "Limit state analysis of hemispherical domes with finite friction," in Structural Analysis of Historical Constructions, Guimarães (Portugal), 2001.

[37] D. D'Ayala and E. Tomasoni, "Three-dimensional analysis of masonry vaults using limit state analysis with finite friction", Int. J. Archit. Heritage, vol. 5, pp. 140-171, 2011.
[38] L. Schueremans and B. Van Genechten, "The use of 3D-laser scanning in assessing the safety of masonry vaults. A case study on the church of Saint-Jacobs", Optics Lasers Eng., vol. 47, pp. 329-335, 2009.

[39] E. Milani, G. Milani, and A. Tralli, "Limit analysis of masonry vaults by means of curved shell finite elements and homogenization", Int. J.Solids Struct., vol. 45, pp. 5258-5288, 2008.

[40] G. Milani, E. Milani, and A. Tralli, "Upper Bound limit analysis model for FRP-reinforced masonry curved structures. Part I: unreinforced masonry failure surfaces", Comput. Struct., vol. 87, no. 23-24, pp. 1516-1533, 2009.

[41] G. Milani, E. Milani, and A. Tralli, "Upper Bound limit analysis model for FRP-reinforced masonry curved structures. Part II: structural analyses", Comput. Struct., vol. 87, no. 23-24, pp. 1534-1558, 2009.

[42] Carini and F. Genna, "Stability and strength of old masonry vaults under compressive longitudinal loads: Engineering analyses of a case study", Eng. Struct., vol. 40, pp. 218-229, 2012.

[43] G. Milani and P.B. Lourenço, "3D non-linear behavior of masonry arch bridges”, Comput. Struct., vol. 110-111, pp. 133-150, 2012.

[44] A.J.S. Pippard, "The approximate estimation of safe loads on masonry bridges", Civil Eng. War, Instit.Civil Eng., vol. 1, 365-273, 1948.

[45] M. Gilbert and C. Melbourne, "Rigid-block analysis to masonry arches", Struct. Eng., vol. 72, pp. 356-361, 1994.

[46] T. Boothby, "Collapse modes of masonry arch bridges", J. Bri. Masonry Soc., vol. 9, no. 2, pp. 62-69, 1995.

[47] M. Gilbert, "Limit analysis of masonry block structures with nonassociative frictional joints using linear programming", Comp. Struc., vol. 84, pp. 873-887, 2006.

[48] G. de Felice and S. De Santis, "Experimental and numerical response of arch bridge historic masonry under eccentric loading", Int. J. Architect. Heritage, vol. 4, no. 2, pp. 115-137, 2010.

[49] Audenaert, P. Fanning, L. Sobczak, and H. Peremans, "2-D analysis of arch bridges using an elasto-plastic material model", Eng. Struct., vol. 30, pp. 845-855, 2008.

[50] Cavicchi, and L. Gambarotta, "Collapse analysis of masonry bridges taking into account arch-fill interaction”, Eng. Struct., vol. 27, no. 4, pp. 605-615, 2005.

[51] Cavicchi, and L. Gambarotta, "Two-dimensional finite element upper bound limit analysis of masonry bridges", Comput. Struct., vol. 84, no. 31-32, pp. 2316-2328, 2006.

[52] M. Gilbert, "Ring: a 2D rigid block analysis program for masonry arch bridges," in $3^{\text {rd }}$ international arch bridges conference, Paris (France), 2001, pp. 109-118.

[53] D. O’Dwyer, "Funicular analysis of masonry vaults", Comput. Struct., vol. 73, no. 1-5, pp. 187-197, 1999.

[54] P. Block P, T. Ciblac, and J.A. Ochsendorf, "Real-time limit analysis of vaulted masonry buildings", Comput. Struc., vol. 84, no. 2930, pp. 1841-1852, 2006.

[55] P. Block and J.A. Ochserdorf, "Thrust network analysis: a new methodology for three-dimensional equilibrium", J. IASS, vol. 48, no. 3, pp. 167-173, 2007.

[56] P. Block, and L. Lachauer, "Three-Dimensional (3D) equilibrium analysis of Gothic masonry vaults", Int. J. Architec. Herit., vol. 8, pp. 312-335, 2014.

[57] Andreu, L. Gil, and P. Roca, "Computational analysis of masonry structures with a funicular model", J. Eng. Mechan. ASCE, vol. 133, no. 4, pp. 473-480, 2007.

[58] Andreu, L. Gil, and P. Roca, "Analysis of masonry structures by funicular networks", Proc. Instit. of Civil Eng.: Eng. and Comput. Mech., vol. 163, no. 3, pp. 147-154, 2010.

[59] F. Fraternali, "A thrust network approach to the equilibrium problem of unreinforced masonry vaults via polyhedral stress functions", Mechan. Res. Commun., vol. 37, no. 2, pp. 198-204, 2010.

[60] F. Fraternali, M. Angelillo, and A. Fortunato, "A lumped stress method for plane elastic problems and the discrete-continuum ap- 
proximation", Int. J. Solids Struc., vol. 39, no. 25, pp. 6211-6240, 2002.

[61] E. Babilio, A. Fortunato, and M. Lippiello, "A stress approach to the equilibrium of masonry domes: a case study," in workshop Wonder Masonry 2007, Edifici in muratura: Progetto e Riabilitazione, 2008.

[62] M. Angelillo, E. Babilio, and A. Fortunato, "Singular stress fields for masonry-like vaults", Continuum Mechanics Thermod., vol. 25, pp. 423-441, 2013.

[63] E. Vouga, M. Höbinger, J. Wallner, and H. Pottmann, "Design of self-supporting Surfaces", in ACM Transactions on GraphicsSIGGRAPH 2012 Conference Proceedings, 2012.

[64] Baratta and O. Corbi, "Stress analysis of masonry vaults and static efficacy of FRP repairs", Int. J. Solids Struc., vol. 44, pp. 80288056, 2007.

[65] Baratta and O. Corbi, "On the equilibrium and admissibility coupling in NT vaults of general shape", Int. J. Solids Struc., vol. 47, pp. 2276-2284, 2010.

[66] Chiarugi, A. Fanelli, and G. Giuseppetti, "Diagnosis and strengthening of the Brunelleschi Dome," in IABSE Symposium, Zürich (Switzerland), 1993.

[67] D. Theodossopoulos, B.P. Sinha, A.S. Usmani, and A.S.J. Macdonald, "Assessment of the structural response of masonry cross vaults", Strain, vol. 38, no. 3, pp. 119-127, 2012.

[68] G. Creazza, A. Saetta, R. Matteazzi, and R. Vitaliani, "Analyses of masonry vaulted structures by using a 3-D damage model," in European Congress on Computational Methods in Applied Sciences and Engineering, ECCOMAS 2000, Barcelona (Spain), 2000.

[69] G. Creazza, A. Saetta, R. Matteazzi, and R. Vitaliani, "Analyses of masonry vaults: a macro approach based on three-dimensional damage model", J. Struct. Eng., vol. 128, no. 5, pp. 646-654, 2002.
[70] P.B. Lourenço, "Computational strategies for masonry structures", Ph.D. Thesis, Delft University Press, Delft (The Netherlands), 1996.

[71] M. Lucchesi, C. Padovani, G. Pasquinelli, and N. Zani, "On the collapse of masonry arches", Meccanica, vol. 32, pp. 327-34, 1997.

[72] M. Pizzolato, M. Monti, P. Pigozzi, and A. Tralli, "The structural analysis of the 3ponti of Comacchio (Ferrara,Italy)", Adv. Mater. Res., vol. 33-134, pp. 531-536, 2010.

[73] M. Lucchesi, C. Padovani, G. Pasquinelli, and N. Zani, "Statics of masonry vaults, constitutive model and numerical analysis", $J$. Mechan. Mater. Struc., vol. 2, no. 2, pp. 221-244, 2007.

[74] J.C. Nagtegaal and I.G. Slater, "A simple nonconforming thin shell element based on discrete Kirchhoff theory," in Nonlinear finite element analysis of plates and shells ASME, New York (USA), 1981.

[75] J. Lubliner, Plasticity Theory. Dover Books (USA), 2005.

[76] P. Suquet, "Analyse limite et homogeneisation", Comptes Rendus de l'Academie des Sciences - Series IIB - Mechanics, vol. 296, 1355-1358, 1983.

[77] Cecchi, G. Milani, and A. Tralli, "Validation of analytical multiparameter homogenization models for out-of-plane loaded masonry walls by means of the finite element method", J. Eng. Mechan. ASCE, vol. 131, no. 2, pp. 185-198, 2005.

[78] P. Foraboschi, "Masonry structures externally reinforced with FRP strips: tests at the collapse," in $1^{\text {st }}$ Convegno Nazionale "Sperimentazioni su Materiali e Strutture", Venice (Italy), 2006.

[79] P. Faccio, P. Foraboschi, and E. Siviero, "Masonry vaults reinforced with FPR strips [In Italian: Volte in muratura con rinforzi in FRP]", L'Edilizia, vol. 7/8, pp. 44-50, 1999.

[80] NTC 2008. Nuove norme tecniche per le costruzioni. Ministero delle Infrastrutture (GU n.29 04/02/2008), Rome, Italy, 2008.

[81] G. Milani and A. Tralli, "A simple meso-macro model based on SQP for the non-linear analysis of masonry double curvature structures", Int. J. Solids Struc., vol. 49, no. 5, pp. 808-834, 2012.

(C) Tralli et al.; Licensee Bentham Open.

This is an open access article licensed under the terms of the Creative Commons Attribution Non-Commercial License (http://creativecommons.org/licenses/by-nc/3.0/) which permits unrestricted, non-commercial use, distribution and reproduction in any medium, provided the work is properly cited. 